\title{
Cerebral state index and brain death
}

\author{
Nunes R.R. ${ }^{1}$, Lopes C.G. ${ }^{2}$, Cavalcante S.L.F. ${ }^{1}$, Ribeiro K.G. ${ }^{1}$, Fernandes \\ M.B.C. ${ }^{1}$, Nunes Filho R.R. ${ }^{3}$
}

1HGF-Hospital Geral de Fortaleza, Dept of Anaesthesiology, Fortaleza, Brazil, 2Hospital Sao Carlos, Dept of Anaesthesiology,
Fortaleza, Brazil, 3Universidad Abierta Interamericana, Dept of Anaesthesiology, Rosario, Argentina

Background: Derived from an analysis of cortical and subcortical parameters of electrical brain activity, the cerebral state index (CSI) is used to monitor depth of anaesthesia. The index is displayed on a monitor fed by two channels of EEG signals from the central nervous system (CNS). Values range from 0 (no activity) to 100 (wake state). Burst suppression rate (BSR) different from zero may indicate hypoperfusion. Electromyographic activity (EMG) is zero when very little or no electrical activity is present in the bulbopontine region, and different from zero in the wake state. Brain death is defined as complete and irreversible loss of brain function, including that of the brain stem.

Case report: A 55-year old patient with a history of systemic arterial hypertension and medicated with atenolol (50 mg/day) was hospitalized due to thunderclap headache and loss of consciousness. Subarachnoid hemorrhage was observed on CT, and EEG activity was suppressed. The patient was intubated, placed on mechanical ventilation and monitored with a CSI device, but was eventually clinically diagnosed with brain death. The CSI-measured parameters were $\mathrm{BSR}=100 \%, \mathrm{CSI}=0, \mathrm{EMG}=0$. At this time, the patient was not under the effect of anesthetics or neuromuscular blockers.

Discussion: The monitored parameters (CSI, BSR and EMG) indicated severe compromise of both cortex and brain stem in a patient diagnosed with brain death, suggesting depth-ofanesthesia monitors may be used to diagnose brain death non-invasively. However, further studies are required to demonstrate the ability of depth-of-anesthesia monitors to satisfy legal requirements for the establishment of brain death.

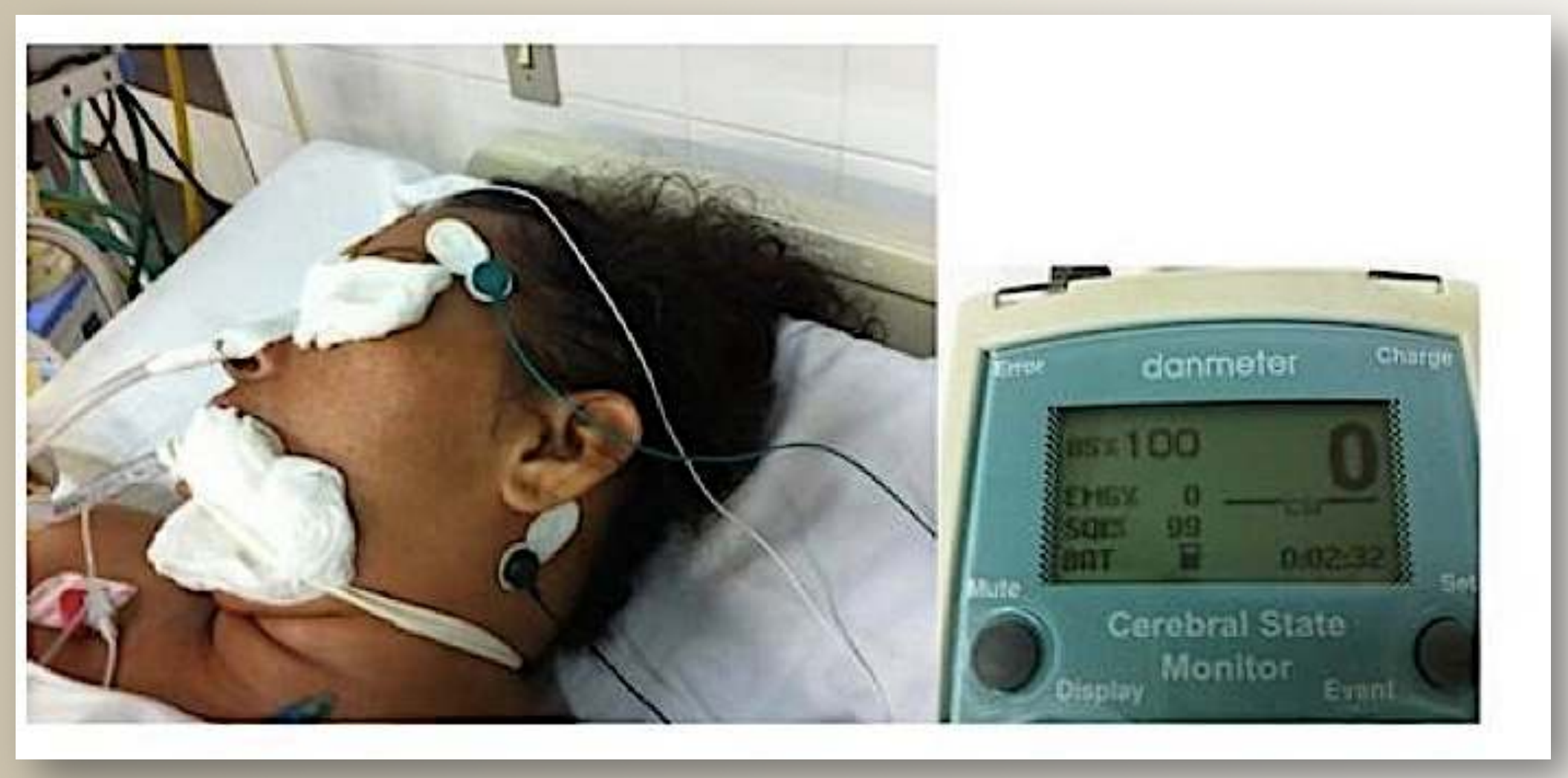

References: Fyntanidou B, Grosomanidis V, Aidoni Z, et al. Bispectral index scale variations in patients diagnosed with brain death. Transplantation Proceedings, 2012,44, 2702-2705.

Jacobsohn E, De Wet C, Tymkew $\mathrm{H}$ et al. Use of the patient state index (PSI) to assist in the diagnosis of perioperative neurological injury and brain death, 2005;19:219-222. 